\title{
EDITORIAL
}

\section{Cerebral mechanisms of mood and behaviour ${ }^{1}$}

There is also another class of philosophers who, having bestowed much diligent and careful labour on a few experiments, have thence made bold to educe and construct systems, resting all other facts in a strange fashion to conformity therewith.

Francis Bacon, Novum Organon, 1620

Despite Bacon's admonition I shall try to construct a vague framework for the consideration of the cerebral mechanisms of mood and behaviour. This will be done from the viewpoint of one mainly concerned with the mechanism of action of drugs which affect the mind, the neuropharmacology of neurotransmitter substances in the brain and their possible involvement in normal and abnormal mental function.

Drugs are exogenous molecules which interact with endogenous molecules and set in train a sequence of events by which a biological process is manipulated. When this molecular interaction is put to therapeutic ends a disordered physiological process is either returned to normal or altered in such a way that the symptoms or manifestations of the disease are ameliorated.

Two points follow from this which are relevant to the biology of normal and abnormal mental function which although self-evident are nonetheless worth stating:

(1) Whatever the rationale for the use of a drug in mental illness, if the drug can be shown by clinical trial to produce benefit, then at some level a potentially definable biological process is involved.

(2) This being so, an understanding of the actions of the drug, whether from studies in man, animals, intact organs, cells, particles or at the molecular level, might give some insight into the pathological processes involved in the mental illness.

There are several corollaries to this. When drugs worsen or change the quality of mental illness similar insight into the underlying processes may be gained by the study of drug action. If certain drugs produce in 'normal' people states of mind, altered behaviour or mental symptoms which mimic certain aspects of spontaneous mental illness, the study of the action of such drugs might lead to the understanding of the biology of the mental illness or symptoms which are mimicked.

It is surely this kind of reasoning which has caused so much attention to be focused upon the role of the brain monoamines, noradrenaline, dopamine and 5-hydroxytryptamine in the neurobiological mechanisms underlying schizophrenia (Grahame-Smith, 1973; Snyder et al. 1974), manic-depressive disease (Schildkraut, 1969; Shopsin et al. 1974; Van Praag, 1974), and the mental syndromes produced by reserpine and psychotomimetic drugs. Reference to Table 1 shows some general current hypotheses concerning the pharmacological actions of some drugs used in the treatment of mental illness or which produce mental syndromes, together with some over-simplified, but quite widely held beliefs linking their pharmacological actions to the aetiology of mental illness. The table does an injustice to the arguments and open-mindedness of the workers propounding the hypotheses but it is these shorthand conclusions which get taken up into the general body of knowledge and which from time to time need open examination.

There is a big snag in this whole approach which might be explained by an artificial analogy. Suppose we were as ignorant of the pathophysiology of heart failure as we are of brain function in mental illness. Suppose too that by serendipity a powerful diuretic was discovered and used empirically with benefit in this uncharted syndrome of 'heart failure'. Intensive investigation of the mode of action of this drug would reveal that its action was on the kidney and the conclusion might be

\footnotetext{
1 Address for correspondence: Dr D. G. Grahame-Smith, MRC Unit and University Department of Clinical Pharmacology, Oxford.
} 
TABLE 1

(a) Some current shorthand hypotheses concerning the role of monoamine function in the causation of mental illness based upon the mode of action of psychotropic drugs

\begin{tabular}{|c|c|c|c|}
\hline Drug & Illness & $\begin{array}{l}\text { Possible mechanism of } \\
\text { action }\end{array}$ & $\begin{array}{c}\text { Shorthand 'aetiological' } \\
\text { conclusions }\end{array}$ \\
\hline $\begin{array}{l}\text { Phenothiazines } \\
\text { Butyrophenones } \\
\text { Thioxanthenes }\end{array}$ & $\begin{array}{l}\text { Schizophrenia } \\
\text { Mania }\end{array}$ & $\begin{array}{l}\text { Dopamine receptor } \\
\text { blockade (see Snyder, } \\
\text { 1974) }\end{array}$ & $\begin{array}{l}\text { Overactivity of } \\
\text { dopaminergic systems }\end{array}$ \\
\hline Tricyclic antidepressants & Depression & $\begin{array}{l}\text { Inhibition of presynaptic } \\
\text { monoamine reuptake } \rightarrow \\
\text { increased monoaminergic } \\
\text { function (see Iversen, } \\
\text { 1973) }\end{array}$ & $\begin{array}{l}\text { Decreased monoaminergic } \\
\text { function }\end{array}$ \\
\hline $\begin{array}{l}\text { Monoamine oxidase } \\
\text { inhibitors }\end{array}$ & Depression & $\begin{array}{l}\text { Decreased metabolism of } \\
\text { monoamines } \rightarrow \text { increased } \\
\text { monoaminergic function } \\
\text { (see Iversen, 1973) }\end{array}$ & $\begin{array}{l}\text { Decreased monoaminergic } \\
\text { function }\end{array}$ \\
\hline Lithium & $\begin{array}{l}\text { 'Prophylaxis' of manic } \\
\text { depressive disease } \\
\text { Mania }\end{array}$ & $\begin{array}{l}\text { Increased functional } \\
\text { activity of 5-HT (see } \\
\text { Green \& Grahame-Smith, } \\
\text { 1975) }\end{array}$ & $\begin{array}{l}\text { Disturbance in } 5-\mathrm{HT} \\
\text { function }\end{array}$ \\
\hline $\mathrm{ECT}$ & Depression & $\begin{array}{l}\text { Increased sensitivity to } \\
\text { behavioural actions of } \\
5-H T \text { and dopamine } \\
\text { (Green \& Grahame-Smith, } \\
\text { 1976) }\end{array}$ & $\begin{array}{l}\text { Decreased } 5-\mathrm{HT} \text { or } \\
\text { dopamine function or } \\
\text { 'sensitivity' }\end{array}$ \\
\hline
\end{tabular}

(b) Drugs 'mimicking' certain aspects of mental illness, their mode of action, and conclusions on aetiology

\begin{tabular}{llll}
\hline \multicolumn{1}{c}{ Drug } & \multicolumn{1}{c}{ Clinical effects } & Action & Conclusions \\
\hline Reserpine & Depression & $\begin{array}{c}\text { Depletion of brain monoamines } \\
\text { (see Iversen, 1973) }\end{array}$ & $\begin{array}{c}\text { Depression 'due to' } \\
\text { decreased monoaminergic } \\
\text { function }\end{array}$ \\
LSD & 'Psychotic' symptoms & $\begin{array}{c}\text { 5-HT agonist/antagonist } \\
\text { (see Grahame-Smith, 1973) } \\
\text { Dopamine release } \\
\text { (see Snyder et al. 1974) }\end{array}$ & $\begin{array}{c}\text { Aspects of schizophrenia } \\
\text { due to 5-HT dysfunction } \\
\text { Aspects of schizophrenia } \\
\text { due to dopaminergic } \\
\text { overactivity }\end{array}$ \\
\hline \hline
\end{tabular}

drawn that this syndrome of 'heart failure' was due to a primary disturbance in renal tubular sodium excretion. We now know that heart failure produces a secondary disturbance in renal sodium excretion and indeed this might be considered a 'normal' response to the altered haemodynamic state produced by heart failure. But although a renal abnormality is involved excessive attention upon it would distract from the primary cause of heart failure.

Consider schizophrenia in this light. Study of the neuropharmacological actions of phenothiazines and other neuroleptics has shown a very impressive correlation between the ability of these compounds to block the actions of dopamine in the brain and their antipsychotic potency. The similarity between amphetamine psychosis and paranoid schizophrenia coupled with the known actions of amphetamine to release brain dopamine also fits in this picture. This has led to the proposition of a 'dopamine hypothesis' for the causation of schizophrenia (see Snyder et al. 1974). I am not exactly sure what is meant by a 'dopamine hypothesis' except that it implies that, somehow or other, a disturbance of dopaminergic neuronal function is involved. That may be so, but it would be naive at this stage to consider it a primary disturbance. The neuroleptics could be equally well acting at a secondary level (Grahame-Smith, 1973). Curare would prevent the physical violence ensuing from a schizophrenic paranoid delusion but it would be foolish to invoke therefore a 
'peripheral cholinergic hypothesis' as a cause of paranoid schizophrenia. I can find nothing in the indirect evidence culled from drug studies implicating dopaminergic mechanisms in schizophrenia which convinces me that an abnormality in dopaminergic function is a primary aetiological factor in schizophrenia. In fact just as the kidney in heart failure is reacting in a normal physiological manner to the change in the haemodynamic state produced by heart failure it might be that the dopaminergic systems in the brain are over-functioning as a 'normal' response to some other more fundamental disturbance influencing them. The neuroleptics then would 'dampen down' this over-activity without affecting the primary disturbance. This reasoning is rather destructive, particularly as I have no idea what the primary disturbance might be, except to speculate upon two possibilities.

(1) A disturbance of sub-cortical systems lying at an even more 'primitive' level than the monoaminergic systems but requiring monoaminergic systems for its linkage to cortical functions.

(2) A subtle, neurohumoral mechanism acting within the brain, altering in a diffuse way the function of monoaminergic systems or the reactivity of neuronal systems to their action.

These are not entirely idle speculations for there are now neurobiological precedences upon which they may be based. In regard to the first it has been shown that in rats the abnormal syndrome of a distinctive form of hyperactivity produced by increasing brain 5-HT levels or by central 5-HT agonists depends for its expression upon brain dopaminergic function. If one interferes with dopaminergic function pharmacologically either by decreasing brain dopamine levels or by pharmacologically blocking the action of brain dopamine then the pharmacological stimulation of brain 5-HT receptors no longer brings about abnormal hyperactive behaviour (see Green \& GrahameSmith, 1975). Thus the precedence is set for dopaminergic function in some way playing a linking or permissive role in the expression of behavioural syndromes produced by the abnormal function of non-dopaminergic pathways.

The second speculation is more hazy but is based upon the effects which small polypeptides, such as thyrotrophin releasing hormone (TRH) (Green \& Grahame-Smith, 1974), melanocyte stimulating hormone release inhibitory factor (MIF) (Plotnikoff et al. 1972), and inhibitors of brain protein synthesis, such as cycloheximide, have on the behaviour of rats and mice. These effects involve changes in the hyperactivity syndromes produced by raising brain 5-HT levels or by the administration of 5-HT agonists, the hyperactivity syndrome produced by raising brain dopamine levels with L-Dopa and a monoamine oxidase inhibitor, and also upon pentylenetetrazol produced convulsions and pentobarbital induced sleeping time. TRH potentiates the hyperactivity syndromes without having much effect on monoamine synthesis and turnover, potentiates pentylenetetrazol induced convulsions and shortens pentobarbital induced sleeping time. Cycloheximide on the other hand does the opposite (Green et al. 1975). The actions of TRH on these behavioural syndromes is not mediated by its action on the pituitary to release $\mathrm{TSH}$, since its behavioural actions occur in hypophysectomized rats. These phenomena suggest that polypeptides like TRH and MIF may in some way modulate the activity of monoaminergic systems or the responses of other neuronal systems to their action. Cycloheximide may be acting by either preventing the synthesis of these putative neuro-modulating polypeptides or by preventing either the release of monoamines or the mediation of their action. However unclear the picture may be at the moment, there is sufficient evidence to consider systems internal to the brain, perhaps mediated by polypeptides, which modulate neuronal activity in monoaminergic systems or systems influenced by them. If indeed this turns out to be the case then an abnormality in such a neurohumoral control mechanism could result in over-activity or under-activity of neuronal systems such as those subserved by the monoamines. The cyclic nature of manic-depressive disease, the latency of action of tricyclic antidepressants, the waxing and waning nature of several psychiatric syndromes, the usual requirement of a course of ECT, are phenomena, the time course of which might be explained by gradual biochemical and pharmacological changes requiring more primary changes in protein/polypeptide synthesis.

It is possible to apply the same types of argument to the actions of tricyclic antidepressants, monoamine oxidase inhibitors and the known effect of reserpine to produce monoamine depletion in the brain and then to the 'serotonin' or 'noradrenaline' hypotheses of manic-depressive disease. 
Here again the monoaminergic theories of aetiology are based upon rather shaky evidence. The evidence from the action of drugs could be equally applied to a monoaminergic function at a secondary level mediating some other more primary disturbance. Such abnormalities in CSF monoamine metabolites in depression as have been demonstrated (particularly the low levels of 5-HIAA and its poor rise on the administration of probenecid (see Van Praag, 1974)) need not necessarily imply a primary abnormality in monoaminergic function. Other criticisms of a biochemical nature can be levelled at the significance of monoamine metabolites in the CSF, particularly in regard to CSF 5-HIAA (Green \& Grahame-Smith, 1975).

Having arrived at the monoamine systems and there being entirely convincing evidence that the drugs considered do have important effects on these systems which in the absence of alternative explanations might well explain their therapeutic activity, it is well to ask the general question 'What do these monoaminergic systems do?' As a general statement one cannot do better than Moore (1971):

Highly integrated neural functions, such as those involving thought processes, which are generally considered to take place in cortical structures may be modified by primitive, chronically active sub-cortical neuronal systems (e.g. limbic and reticular activating systems). Accordingly a dysfunction of these delicately balanced primitive systems may result in derangement of mental processes and behaviour.

Because we know so little of the functional neuroanatomy of human thought processes, mood and behaviour, it is necessary to play the game of association between the effects of drugs in man, the known actions of drugs, the functional neuroanatomy of animal behaviour, and the effects of drugs with known actions on animal behaviour and to try by this game, by intuitive reasoning and with a fair share of serendipity, to come out with some sensible answers.

Crucial to all these considerations is of course the mode of action of the relevant drugs. This can be a very complex matter and we ourselves have been made aware of this complexity through our study of the effect of lithium, phenytoin, reserpine, phenothiazines, tricyclic antidepressants, dopamine depletion, inhibitors of brain protein synthesis and electroconvulsive shock on the hyperactivity syndrome in rats produced by raising brain 5-HT levels by the administration of tryptophan and a monoamine oxidase inhibitor or by the administration of 5-HT agonists such as 5-methoxy N,N-dimethyltryptamine or 5-methoxytryptamine (see Green \& Grahame-Smith, 1976). Drugs may affect one or more of the following functions of 5-HT and its behavioural effect: the synthesis, compartmentation, release, re-uptake and immediate post-synaptic action, or the function of other neuronal pathways mediating or permitting the immediate post-synaptic action of 5-HT to be expressed as a behavioural response.

It is also gradually becoming apparent that the chronic effects of drugs are quite different and involve unsuspected pharmacological actions on monoamine metabolism and function. Two examples will illustrate this. Acute chlorpromazine administration undoubtedly blocks the action of dopamine in the brain and will inhibit the hyperactivity syndromes produced by increasing brain 5-HT or dopamine function in the brain. Chronic chlorpromazine treatment however leads to a situation in which, when chlorpromazine is stopped, the hyperactivity produced by increasing brain 5-HT or dopamine function is enhanced, suggesting that perhaps 5-HT or dopamine receptor supersenstitivity has been induced by chronic pharmacological inhibition, though there is little direct evidence yet that this is so. A second example involves the effects of electroconvulsive shock in rats. One electroconvulsive shock does not alter the hyperactivity response produced by increasing brain 5-HT or dopamine function. However, a daily electroconvulsive shock for 10 days or one electroconvulsive shock twice weekly for 4 weeks greatly enhances the hyperactivity response produced by increasing brain 5-HT and dopamine function. We have no idea yet of the mechanism by which these changes are brought about. One cannot help feeling though, that in view of all the other evidence implicating changes in monoamine function in the actions of drugs which alter mood and behaviour, that this action of electroconvulsive shock on monoamine function has some meaning in regard to the therapeutic effect of ECT in depression. The long-term changes produced by 


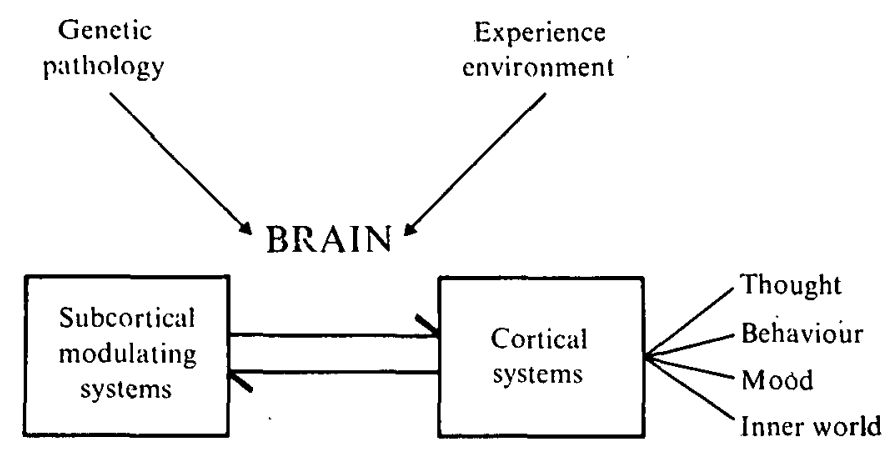

Neurotransmitters

Neuromodulators

Fig. 1. Personal fantasy framework for the cerebral mechanisms of mood and behaviour.

drugs and other procedures are not unique in biochemical terms to the brain. The pituitary trophic hormones produce chronic changes in the target endocrine glands, often expressed as an increased secretory sensitivity to the action of the trophic hormone. Biochemical 'memory' is a common phenomenon.

How can all this be integrated into a general framework on which to consider the cerebral mechanisms of mood and behaviour. My personal viewpoint is summarized in Fig. 1 which is a grossly simplified working scheme.

I believe that general principles are now sufficiently well founded to allow certain statements to be made which bridge the gap which has so long existed between those whose views relied entirely upon psychological factors such as the effect of learning, experience and environment as being the sole factor involved in the production of mental states, to the exclusion of brain biology, and those who have relied solely upon brain biology as an explanation for all mental function.

One function of the brain is to record and process incoming information and experience. Undoubtedly there are neurobiological mechanisms underlying this recording, processing and retention and its effects upon pre-existing brain function. Exactly what these neurobiological mechanisms are we do not yet know but some little progress has been made in regard to the involvement of synthesis of new protein in simple memory (Cooper et al. 1970). The ability to record, process and retain incoming information obviously depends upon brain structure and function. Pathology, whether it be genetic or acquired, must affect these functions to some extent just as normal structure and normal function must be two of the determinants of the effect which experience has upon the existing brain function. This recording of experience in biochemical and pharmacological terms can be borne out by the effect stress has on monoamine synthesis and metabolism in animal brains and by the effect of drugs altering receptor sensitivity. The involvement of structure and function of the brain in its normal functions of recording experience, thinking, feeling and behaviour is of paramount importance in considering the neurobiology of psychiatric disease. To try and view psychiatric disease in isolation from the patient's environment, problems and past experience is as much biological nonsense as trying to understand angina without understanding that the heart is a muscular pump that works harder on exercise. Just as angina can be relieved by decreasing the amount of work that the heart has to do or by an adaptative change in collateral circulation, so one may presume that functional brain changes can be brought about to relieve anxiety and depression through environmental manipulation and psychotherapy. The 'psychological' and 'biological' factors in depression are brought together very well in a paper by Akiskal \& McKinney (1973). 
I see nothing inherently impossible in regard to the change in mind purported to be brought about by psychoanalysis. Readaptation and relearning presumably are the mechanisms of these forms of non-physical therapy. One of the interesting things about the brain is that through 'the inner world of the mind' it is able to manipulate its own function. This, as far as I know, does not occur in any other organ, at least not on a conscious level.

What of the relationship between sub-cortical modulating systems and cortical systems, the latter being presumed to be the site of conscious emotion and thought and being the site from which complex behavioural patterns are formulated? I tend to think of the cortical systems acting to subserve refined and sophisticated mental function but being influenced by a background of subcortical modulating system function. If one considers the monoaminergic systems, their ramifications from their nuclei in sub-cortical regions to the cortex are staggering. It would not be surprising if when their function was disturbed either primarily or secondarily, a very general abnormality in cortical function, such as might be demonstrated by a diffuse disorder of thought, a change of mood or general change in behaviour, resulted. While the pathways by which sub-cortical monoaminergic systems might influence the function of the cortex are to some extent known, much less seems to be known about how cortical function might 'feed-back' to influence monoaminergic function, but undoubtedly such mechanisms will be found to exist.

I would dearly love to be able to see into the future of psychiatry. How are psychiatrists going to cope with the increasing knowledge knitting together the interrelationships between experience, biological brain function and subsequent mental function and the introduction of psychotropic drugs of greater selectivity requiring a good deal of background knowledge for their proper use? It will be very interesting to see the subject evolve on this background.

D. G. GRAHAME-SMITH

\section{REFERENCES}

Akiskal, H. S. \& McKinney, W. T. (1973). Depressive disorders: toward a unified hypothesis. Science 182, 20-29.

Cooper, J. R., Bloom, F. E. \& Roth, R. H. (1970). The Biochemical Basis of Neuropharmacology, Chapter 9. Oxford University Press: London.

Grahame-Smith, D. G. (1973). Pharmacological aspects of schizophrenia. Biochemical Society Special Publications 1, 197-207.

Green, A. R. \& Grahame-Smith, D. G. (1974). TRH potentiates behavioural changes following increased brain 5hydroxytryptamine accumulation in rats. Nature 251, 524-526.

Green, A. R. \& Grahame-Smith, D. G. (1975). 5-hydroxytryptamine and other indoles in the central nervous system. In Handbook of Psychopharmacology, vol. 3 (ed. S. D. Iversen, L. L. Iversen \& S. H. Snyder), pp. 169-245. Plenum Press: New York.

Green, A. R. \& Grahame-Smith, D. G. (1976). The effect of drugs on the processes regulating the functional activity of brain 5-hydroxytryptamine. Nature 260, 487-491.

Green, A. R., Heal, D. J. \& Grahame-Smith, D. G. (1975). Lack of change in the sensitivity of rat caudate nucleus adenyl cyclase to dopamine when TRH and cycloheximide produce opposite effects on behavioural responses to certain centrally active drugs. In Chemical Tools in Catecholamine Research, vol. 2 (ed. O. Almgren. A. Carlsson \& J. Engel), pp. 265-274. North Holland/American Elsevier.
Iversen, L. L. (1973). Monoamines in the mammalian central nervous system and the action of antidepressant drugs. Biochemical Society Special Publications 1, 81-96.

Moore, K. E. (1971). In Introduction to Psychopharmacology (ed. R. H. Rech \& K. E. Moore), p. 117. Raven Press: New York.

Plotnikoff, N. P., Prange, A. J., Breese, G. R., Anderson, M. S. \& Wilson, I. C. (1972). TRH: Enhancement of DOPA activity by a hypothalamic hormone. Science 178 , 417-418.

Schildkraut, J. J. (1969). Rationale of some approaches used in the biochemical studies of the affective disorders: The pharmacological bridge. In Psychochemical Research in Man (ed. A. J. Mandell \& M. P. Mandell). Acadenic Press: New York.

Shopsin, B., Wilk, S., Sathananthan, G., Gershon, S. \& Davis, K. (1974). Catecholamines and affective disorders raised. A critical assessment. Journal of Nervous and Mental Disease 158, 369-383.

Snyder, S. H., Banerjee, S. P., Yamamura, H. I. \& Greenburg, D. (1974). Drugs, neurotransmitters and schizophrenia. Science 184, 1243-1253.

Van Praag, H. M. (1974). Towards a biochemical typology of depression? Pharmakopsychiatria 7, 281-292. 